\title{
Resting-state EEG distinguishes depression in Parkinson's disease
}

\section{Arturo I Espinoza ${ }^{1}$, Patrick May ${ }^{2}$, Md Fahim Anjum ${ }^{2}$, Arun Singh $^{3}$, Rachel C Cole ${ }^{1}$, Nicholas} Trapp $^{4}$, Soura Dasgupta ${ }^{2}$, Nandakumar S Narayanan ${ }^{1}$

${ }^{1}$ Department of Neurology, University of Iowa, ${ }^{2}$ Department of Electrical and Computer Engineering, University of Iowa, ${ }^{3}$ Division of Basic Biomedical Sciences, Sanford School of Medicine, University of South Dakota, ${ }^{4}$ Department of Psychiatry, University of Iowa

\section{*Corresponding Author}

Nandakumar Narayanan

nandakumar-narayanan@uiowa.edu

169 Newton Road

Pappajohn Biomedical Discovery Building-5336

University of Iowa, Iowa City, 52242

319-353-5698 
medRxiv preprint doi: https://doi.org/10.1101/2022.02.16.22271060; this version posted February 19, 2022. The copyright holder for this preprint

(which was not certified by peer review) is the author/funder, who has granted medRxiv a license to display the preprint in perpetuity.

It is made available under a CC-BY-NC-ND 4.0 International license.

\section{HIGHLIGHTS}

43

44

45

46

47

48

49

- We used EEG to analyze depression in Parkinson's disease.

- Depressed Parkinson's patients had distinct spectral EEG features.

- Machine-learning algorithms could accurately distinguish depression in Parkinson's disease. 


\section{ABSTRACT}

51 Introduction: Depression is a non-motor symptom of Parkinson's disease (PD). PD-related

52 depression is hard to diagnose and the neurophysiological basis is poorly understood. Depression

53 can markedly affect cortical function, which suggests that scalp electroencephalography (EEG)

54 may be able to distinguish depression in PD.

55 Methods: We recruited 18 PD patients, 18 PD patients with depression, and 12

56 demographically-similar non-PD patients with clinical depression. All patients were on their

57 usual medications. We collected resting-state EEG in all patients and compared cortical brain

58 signal features between patients with and without depression. We used a machine-learning

59 algorithm that harnesses the entire power spectrum (linear predictive coding of EEG Algorithm for PD: LEAPD), to distinguish between groups.

61 Results: We found differences between PD patients with and without depression in the alpha

62 band $(8-13 \mathrm{~Hz})$ globally and in the beta $(13-30 \mathrm{~Hz})$ and gamma $(30-80 \mathrm{~Hz})$ bands in the central

63 electrodes. From two minutes of resting-state EEG we found that LEAPD-based machine

64 learning could robustly distinguish between PD patients with and without depression with $97 \%$

65 accuracy, and between PD patients with depression and non-PD patients with depression with

$66100 \%$ accuracy. We verified the robustness of our finding by confirming that the classification

67 accuracy declines gracefully as data are truncated.

68 Conclusions: We demonstrated the efficacy of the LEAPD algorithm in identifying PD patients

69 with depression from PD patients without depression and controls with depression. Our data

70 provide insight into cortical mechanisms of depression and could lead to novel

71 neurophysiologically-based biomarkers for non-motor symptoms of PD. 


\section{INTRODUCTION}

Depression is a prominent non-motor symptom of Parkinson's disease (PD) [1]. PD-

74 related depression affects $\sim 20 \%-40 \%$ of PD patients, several times the expected prevalence

75 within this population [2]. Importantly, this aspect of PD is often missed by physicians,

76

77

78

79

80

81

82

contributing to morbidity and decreased quality of life [3-6]. Despite its significance and impact [7], it is unclear which brain circuits contribute to PD-related depression [8]. Determining which brain circuits are involved could lead to the development of new diagnostic tools to identify PDrelated depression, as well as targeted treatments such as neuromodulation [9]. A fast and accurate neurophysiologically-based diagnostic tool may also facilitate neuromodulation. In addition, a better understanding of depression in PD may help us illuminate fundamental mechanisms of both diseases.

PD and depression involve several overlapping circuits and associated neurotransmitters, including dopamine and serotonin [10]. These projection systems affect cortical physiology [11,12]. Cortical regions can be profoundly dysfunctional in PD [13] and in depression [14]. One technique that is particularly well-suited to capture cortical neurophysiology is electroeencephalography (EEG), which uses scalp electrodes to record activity from the cortex via an array of scalp electrodes. An early EEG study comparing depressed and non-depressed PD patients found widespread differences in alpha bands $(8-13 \mathrm{~Hz})$ in posterior and frontal sites [7].

$$
\text { Quantititave EEG (qEEG) studies have found spectral differences that distinguished PD vs }
$$
depresson [15]. Furthermore, prefrontal cortical regions are responsive to targeted interventions, such as transcranial magnetic stimulation [16]. Here, we tested the hypothesis that spectral

3 features of EEG can distinguish PD patients with depression. 
95 without depression. We compared these data with control patients with depression but without

96 PD. We report three main results. First, PD patients with depression had globally attenuated

97 alpha $(8-13 \mathrm{~Hz})$ rhythms, as well as attenuated central beta $(13-30 \mathrm{~Hz})$ and gamma $(30-80 \mathrm{~Hz})$

98 rhythms relative to PD patients without depression. Second, PD patients with depression had

99 strong global differences in gamma rhythms relative to non-PD patients with depression. Third,

100 we used a linear predictive coding of EEG Algorithm for PD (LEAPD) formulated by Anjum et

101 al. [17,20], which provides binary classification based on resting-state EEG power spectra.

102 LEAPD-based classification accurately identified PD patients with depression relative to PD

103 patients and non-PD depressed patients. Collectively, these data implicate cortical rhythms in

104 PD-related depression, which could lead to novel targeted therapies or new diagnostic

105 biomarkers for this important non-motor aspect of PD.

106 


\section{METHODS}

\section{Participants}

36 PD patients (11 women; Table S1) were recruited from clinics at the University of Iowa. A movement-disorders physician examined all PD patients to verify that they met the diagnostic criteria recommended by the United Kingdom PD Society Brain Bank criteria. Depression was quantified using the Geriatric Depression Scale in PD patients; a score of 5 to 15 was considered depressed). In addition, the motor Unified Parkinson's Disease Rating Scale (UPDRS) was administered to all PD patients by a qualified rater, along with other clinical metrics, such as the Montreal Cognitive Assessment (MOCA) and behavioral assays. Data were collected with patients taking all medications as prescribed and PD patients were in the "ON" state. See our prior work for details of cognitive assessments [18]. Demographics and other clinical details are presented in Table S1 and were compared between groups by non-parametric Wilcoxon tests. We recruited 12 demographically-similar depressed patients without PD (5 women; Table S1) from the University of Iowa's depression and neuromodulation clinic. These patients were diagnosed with depression by the Patient Health Questionnaire-9, with a value of 9 to 27 . A psychiatrist evaluated all patients, and patients took their medications as prescribed.

We obtained written informed consent from all participants according to the University of Iowa's Institutional Review Board (IRB). Demographics of patients and control subjects are summarized in Table S1.

\section{EEG recording and analysis}

Resting-state EEG was collected from patients while they sat in a quiet room with their eyes open for two minutes. Scalp EEG signals were collected from 64 channels of an EEG 

frequency of $500 \mathrm{~Hz}$. Electrode $\mathrm{Pz}$ was used as a reference, and electrode $\mathrm{FPz}$ was used as the ground. We used recording methods described previously in detail using a custom EEG cap with

We also removed FP1, FP2, FT10, TP9, and TP10 channels as these channels are often contamined by artifact, resulting in 56 channels for pre- and post-processing. EEG activity at the reference electrode $\mathrm{Pz}$ was recovered by computing the average reference. Bad channels and bad epochs were identified using the FASTER algorithm and the pop_rejchan function from EEGLAB and were then interpolated and rejected, respectively. Eye blinks were removed using independent component analysis (ICA). All channels were low-pass filtered at $100 \mathrm{~Hz}$. Power was calculated using the pwelch function and was normalized to the mean power between 0-100 $\mathrm{Hz})$, theta $(4-8 \mathrm{~Hz})$, alpha $(8-13 \mathrm{~Hz})$, beta $(13-30 \mathrm{~Hz})$, and gamma (30-80 Hz; Figure 1) bands.

\section{Machine learning using Linear predictive coding algorithms for PD (LEAPD)}

LEAPD is an algorithm for binary classification of the spectral content of EEG signals.

147 This approach was developed by Anjum et al. [17,20] to distinguish between PD patients and

148 control participants. We implemented LEAPD to compare PD patients with depression (PDDEP)

149 vs PD patients without depression (PD) and PDDEP vs depressed patients without PD (DEP). In

150 particular, a LEAPD index between 0 and 1 is generated for each EEG recording, using the

151 procedure outlined below. In each of the two problems, a threshold of 0.5 is used to distinguish

152 between two groups. For example, if the LEAPD index for an EEG recording is below 0.5 then it 153 is deemed to be in Group A and if above 0.5 it is classified as belonging to Group B. 
In LEAPD, an EEG time series from a channel is processed using linear predictive coding (LPC) to encode the signal into coefficients of an autoregressive model minimizing the square of the prediction error [21] for that time series. The number of coefficients $n$, is called the 157 LPC order. These coefficients are put in a vector of dimension $n$ with one entry for each coefficient. An LPC vector is generated by substracting the mean. Each LPC vector is viewed as a point in the $n$-dimensional space. LPC vectors of each group lies on distinct affine subspaces. For example those for PDDEP roughly lie on one affine subspace while those of PD on another. An affine subspace is the generalization of a one-dimensional line or a two-dimensional plane in larger dimensions. The LEAPD index of a recording is as below, where $D_{1}$ is the distance of its LPC vector from the affine subspace of one group and $D_{2}$ is the distance from the affine subspace of the other group:

$$
L E A P D \text { Index }=\frac{D_{2}}{D_{1}+D_{2}} .
$$

Principal Component Analysis (PCA) is used to identify the affine subspace of a given dimension that best fits the LPC vectors of each group. Parameters used to control the learning process include: (1) the cutoff frequencies of the filter used to process the EEG data; (2) the length of the LPC vector (LPC order); and (3) the dimension of the affine subspace.

We quantified differences between LEAPD values for each channel using non-parametric

171 Wilcoxon ranksum tests. In addition, we used a classifier to calculate the accuracy of PD vs

172 PDDEP and DEP vs PD at each channel. Two-channel LEAPD values were computed by taking

173 the geometric mean of the LEAPD values for each channel. We then used a classifier on all two-

174 channel combinations, and we presented results only from selected high-performing

175 combinations. 
As the dataset was small, we could not perform out-of-sample prospective tests to

177 validate the accuracy of the model. However, we tested the robustness of the results by

178 examining LEAPD performance on truncated data. In all instances leave-one-out cross validation

179 (LOOCV) was used to quantify performance. LOOCV uses the entire dataset without one test

180 sample to predict each test sample, which protects against the overfitting common with small

181 datasets. We report data from individual channels and combinations of channels that yielded the

182 a) highest accuracy in discriminating PD vs PDDEP and PDDEP vs DEP, and b) were the most

183 robust on truncated data.

184

185

186 
medRxiv preprint doi: https://doi.org/10.1101/2022.02.16.22271060; this version posted February 19, 2022. The copyright holder for this preprint (which was not certified by peer review) is the author/funder, who has granted medRxiv a license to display the preprint in perpetuity.

It is made available under a CC-BY-NC-ND 4.0 International license .

\section{RESULTS}

PD patients with and without depression had similar age $(p=0.23)$, motor function as measured by UPDRS $(p=0.22)$, and cognitive profiles as measured by the MOCA $(p=0.94$ value; Table S1). We collected resting-state EEG data and compared scalp topography of relative power for PD patients vs PD patients with depression (PDDEP) at delta (1-4 Hz), theta (4-8 Hz), alpha $(8-13 \mathrm{~Hz})$, beta $(13-30 \mathrm{~Hz})$, and gamma bands $(30-80 \mathrm{~Hz}$; Figure 1A). We also compared scalp topography for PDDEP vs non-PD patients with depression (DEP; Figure 1B). These data illustrate that there can be band-specific differences that distinguish depression in PD.

Our machine learning approach, LEAPD, compress power spectra into a series of autoregressive coefficients that holistically captures the shape of each power spectra with a few numbers $[17,20]$. Here, we used LEAPD to classify PD vs PDDEP and PDDEP vs DEP from single channels, as well as combinations of two channels (Figure 2).
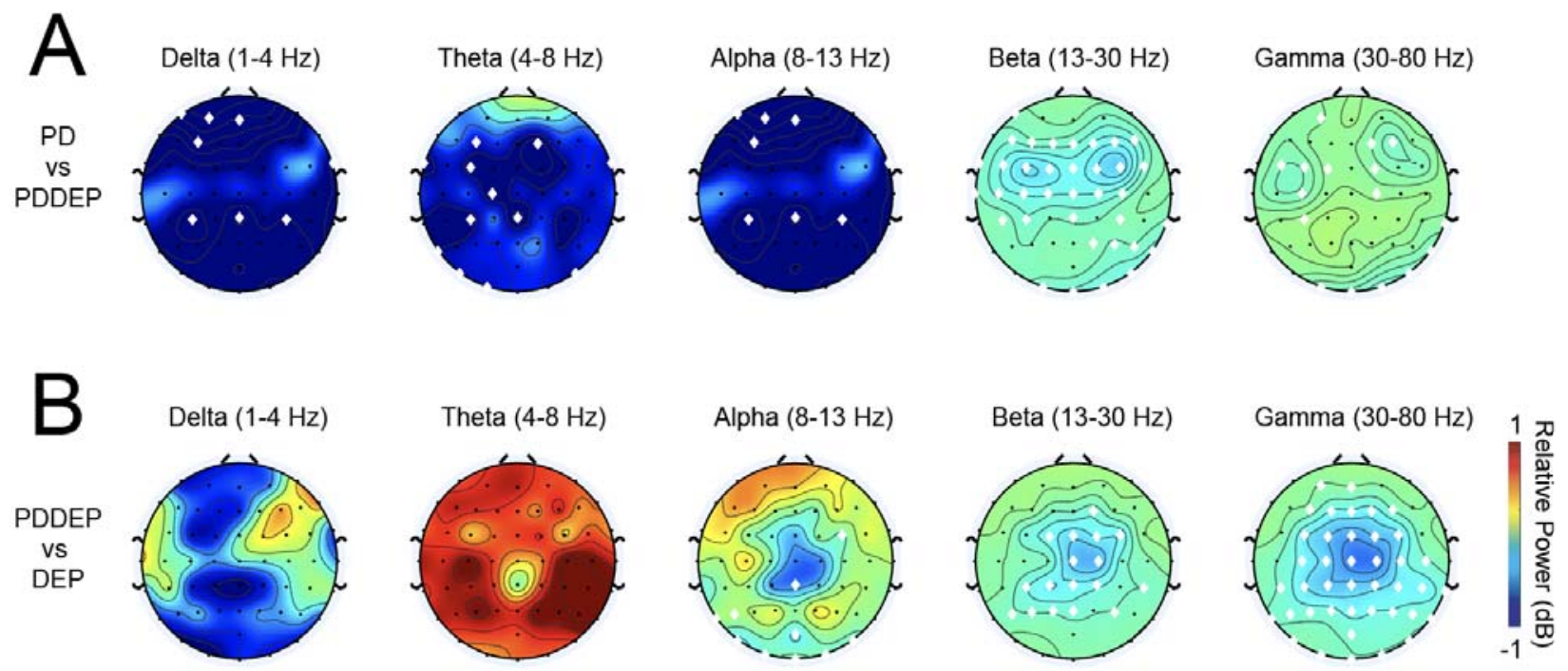

Figure 1: Scalp topography of relative EEG power in PD patients with depression . A) Relative power in PD patients with depression (PDDEP) compared to PD patients without depression for delta (1-4 Hz), theta (4-8 Hz), alpha $(8-13 \mathrm{~Hz})$, beta $(13-30 \mathrm{~Hz})$, and gamma $(30-80 \mathrm{~Hz})$. B) Relative power in PDDEP compared to non-PD patients with depression (DEP). Electrodes are indicated by black dots; electrodes with significant differences between groups via ranksum testing are shown with white diamonds. Data from 18 PD, 18 PDDEP and 12 DEP. 
We first used LEAPD to discriminate 18 PD from

20018 PDDEP patients across all EEG electrodes (Figure

201 3A). Single-channel accuracy for channel CP3 was $86 \%$

202 and for TP8 was 86\% (Figure 3A). Combining both CP3

203 and TP8 resulted in an overall LOOCV classification

204 accuracy of 97\%. These channels had distinct LEAPD

205 indices between PD and PDDEP (CP3: $p=0.00009$,

206 Cohen's d = 1.8; TP8: $p=0.0 .00004$, Cohen's d = 1.8;

207 CP3+TP8: $p<0.001$; Cohen's d = 3.25; Figure 3B).

208 Receiver-operator curves (ROCs) for these channels in

209 predicting PD vs PDDEP are shown in Figure 3C.

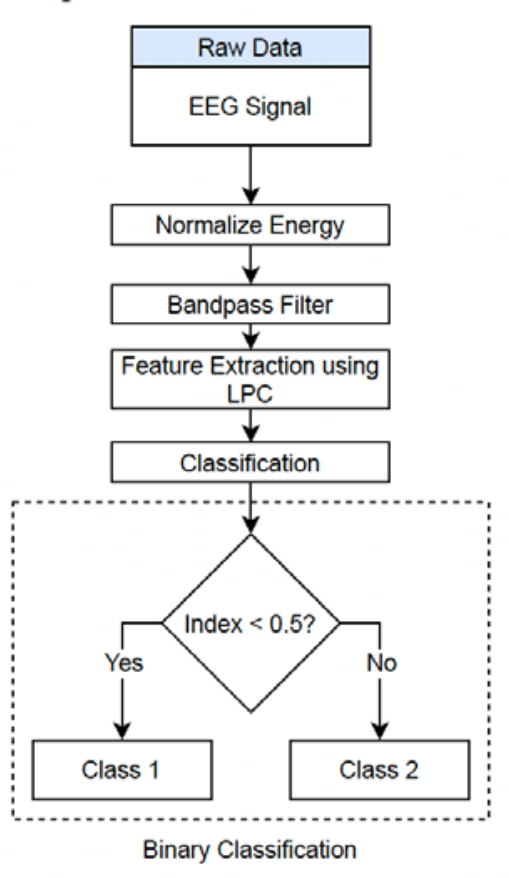

Figure 2: LEAPD Classification approach: Flow chart of classification. 

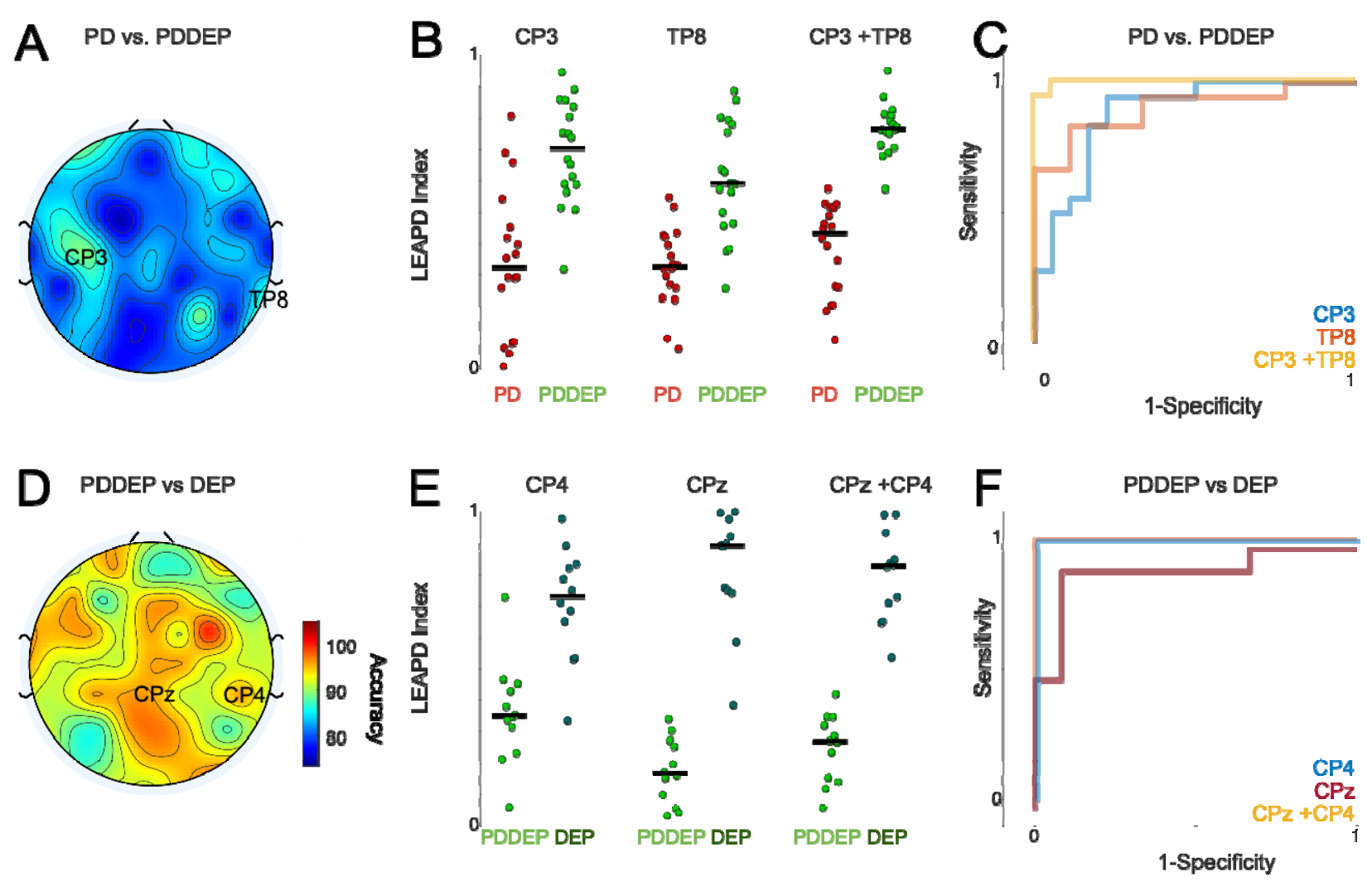

Figure 3: Machine-learning classification of LEAPD. A) We constructed LEAPD indices from LPC coefficients from electrodes CP3 and TP8 for PD patients without depression (PD) vs PD patients with depression (PDDEP). B) Receiveroperating curves (ROC) for single-channel performance of CP3, TP8, and CP3+TP8 combined, and C) channel performance across single electrodes. Data from 18 PD and 18 PDDEP patients. D) We also generated LEAPD indices for PDDEP (green) compared to depressed patients without PD (DEP; dark green) at $\mathrm{CP} 4, \mathrm{CPz}$, and $\mathrm{CP} 4+\mathrm{CPz}$ combined. E) ROC curves and F) single channel performance across single electrodes. Data from 12 PDDEP and 12 DEP patients.

Additionally, we performed a truncation analysis of CP3, TP8, and CP3+TP8 combined

EEG data were truncated from full-length samples to samples that were a fraction of the original 
medRxiv preprint doi: https://doi.org/10.1101/2022.02.16.22271060; this version posted February 19, 2022. The copyright holder for this preprint (which was not certified by peer review) is the author/funder, who has granted medRxiv a license to display the preprint in perpetuity.

It is made available under a CC-BY-NC-ND 4.0 International license .

EEG behavior between classes, rather than an artifact of overfitting. It is notable that accuracy of

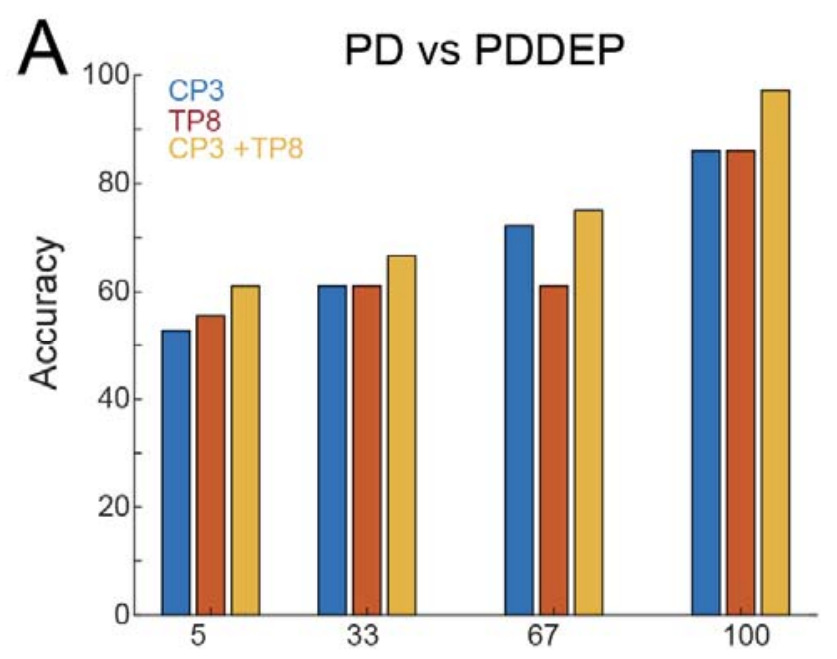

Percent Length of Original Sample

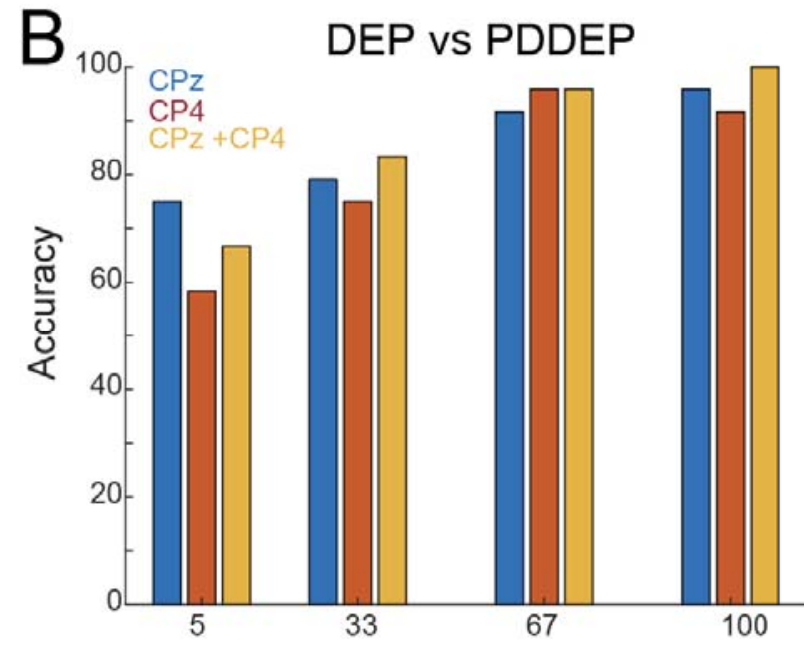

Percent Length of Original Sample

Figure 4: I runcation analysiS of LEAPU-based classitication. A) Data trom PD VS PDNEP tor $5,35,0 /$, and 1 , of data for PDDEP vs PD for CP3, TP8, and CP3+TP8 and B) PDDEP vs DEP for CP4, CPz, and CP4 + CPz. 


\section{DISCUSSION}

We explored the cortical basis of depression in PD using resting-state scalp EEG. We found that PD patients with depression had central differences in beta and gamma rhythms. We used LEAPD, a spectral machine-learning approach, to detect differences in EEG signals from two minutes of resting-state data from a single electrode, achieving accuracies of $97 \%$ for PD patients with and without depression and $100 \%$ for PD vs non-PD patients with depression. These data indicate that PD patients with depression can be accurately differentiated from PD patients without depression and from depressed non-PD patients using machine learning.

244 dysfunctional alpha rhythms in depressed patients [24,25], a finding that we report here in $\mathrm{PD}[26]$ and our data here indicate that depression decreases resting-state beta, alpha, and

247 gamma rhythms in PD. We find that many cortical regions are implicated in PD-related depression, including prefrontal and parietal regions that have been found in prior studies of depression $[14,27]$

These data suggest that EEG, which is relatively inexpensive and ubiquitously available,

251 can identify PD patients with depression. This is important because depression can be missed in

252 PD [3-5], and electrophysiological diagnostic tools may aid in this effort. We report that our 253 spectral approach can rapidly, robustly, and accurately identify EEG signals from PD patients 254 with depression. Our results are in line with previous efforts to use LEAPD to identify local field 255 potentials from animal models of PD and EEG data recorded from PD patients and controls $256[17,20]$. LEAPD-based techniques might have additional utility in settings where 
neurophysiology is common, such as during deep-brain stimulation surgeries, and they may be helpful for closed-loop control applications. Apart from being robust and accurate, LEAPD is amenable to fast implementation and can serve as a trigger mechanism for brain stimulation. rhythms [7]. Our study is supportive of these differences, and we are able to localize these results to the left frontal electrodes. In addition, we find broader differences over central electrodes in beta and gamma bands, which may have been averaged out in prior work that averaged EEG signals from multiple electrodes. Finally, we used advanced machine-learning to

267 distinguish PD patients with depression from both PD patients and non-PD patients with 268 depression. Recent work has reported frontal differences in sleep in PD patients with 269 depression[28], as well as differences between midline event-related potentials between PD 270 patients with and without depression [29]. Our study extends these findings and helps define the 271 spectral topography of resting-state EEG in PD patients with depression, and demonstrates the 272 potential of machine-learning for identifying PD patients with depression. In this manuscript, we illustrate these effects from relatively high-performing channels:

$274 \mathrm{CP} 3 / \mathrm{TP} 8$ in PD vs PDDEP and CP4/CPz in PDDEP vs DEP. We chose these exemplars to 275 illustrate high-performing channel combinations from each comparison. However, we note that 276 channels also had high performance, and could be used for classification and identificiation of 277 depression in PD. 
280 medicated, and it is possible that medications could influence these EEG signals [30]. Third, our

281 method of diagnosing depression and quantifying symptom burden in PD patients was distinct

282 from the method used with non-PD patients, limiting comparisons between these groups. Finally,

283 our LEAPD approach did not include an out-of-sample prospective test, though the truncation

284 analysis does remove concerns of overfitting. Despite these shortfalls, our findings describe

285 spectral changes in PD patients with depression compared to PD patients without depression and

286 non-PD patients with depression. We report that LEAPD-based machine learning approaches can

287 identify EEG signals from PD patients with depression. These data could help illuminate the

288 cortical neurophysiology of PD-related depression and could help lead to new biomarkers or

289 diagnostic tools. 
medRxiv preprint doi: https://doi.org/10.1101/2022.02.16.22271060; this version posted February 19, 2022. The copyright holder for this preprint (which was not certified by peer review) is the author/funder, who has granted medRxiv a license to display the preprint in perpetuity. It is made available under a CC-BY-NC-ND 4.0 International license .

\section{AUTHOR DECLARATION}

293 None of the authors have any potential conflicts of interest to disclose.

294

295 ACKNOWLEDGEMENTS

296 This data was supported by NIH P20NS123151 and R01NS100849 to NSN.

297

298 


\section{References}

301

302

303

304

305

306

307

308

309

310

311

312

313

314

315

316

317

318

319

320

321

322

323

324

325

326

327

328

329

330

331

332

333

334

335

336

337

338

339

340

341

342

343

344

345

346

347
[1] K.R. Chaudhuri, P. Odin, The challenge of non-motor symptoms in Parkinson's disease, Prog. Brain Res. 184 (2010) 325-341. https://doi.org/10.1016/S0079-6123(10)84017-8.

[2] A. Lieberman, Depression in Parkinson's disease - a review, Acta Neurol. Scand. 113 (2006) 1-8. https://doi.org/10.1111/j.1600-0404.2006.00536.x.

[3] H. Allain, S. Schuck, N. Maudui, Depression in Parkinson's disease: Must be properly diagnosed and treated to avoid serious morbidity, BMJ. 320 (2000) 1287-1288. https://doi.org/10.1136/bmj.320.7245.1287.

[4] S. Muzerengi, H. Lewis, M. Edwards, E. Kipps, A. Bahl, P. Martinez-Martin, K.R. Chaudhuri, Nonmotor symptoms in Parkinson's disease: an underdiagnosed problem, Aging Health. 2 (2006) 967982. https://doi.org/10.2217/1745509X.2.6.967.

[5] M.H.M. Timmer, M.H.C.T. van Beek, B.R. Bloem, R.A.J. Esselink, What a neurologist should know about depression in Parkinson's disease, Pract. Neurol. 17 (2017) 359-368. https://doi.org/10.1136/practneurol-2017-001650.

[6] A.F.G. Leentjens, M. Van den Akker, J.F.M. Metsemakers, R. Lousberg, F.R.J. Verhey, Higher incidence of depression preceding the onset of Parkinson's disease: a register study, Mov. Disord. Off. J. Mov. Disord. Soc. 18 (2003) 414-418. https://doi.org/10.1002/mds.10387.

[7] S.R. Filipović, N. Čovičković-Šternić, M. Stojanović-Svetel, D. Lečić, V.S. Kostić, Depression in Parkinson's disease: an EEG frequency analysis study, Parkinsonism Relat. Disord. 4 (1998) 171178. https://doi.org/10.1016/S1353-8020(98)00027-3.

[8] D. Aarsland, S. Påhlhagen, C.G. Ballard, U. Ehrt, P. Svenningsson, Depression in Parkinson disease-epidemiology, mechanisms and management, Nat. Rev. Neurol. 8 (2012) 35-47. https://doi.org/10.1038/nrneurol.2011.189.

[9] N.L. Bormann, N.T. Trapp, N.S. Narayanan, A.D. Boes, Developing Precision Invasive Neuromodulation for Psychiatry, J. Neuropsychiatry Clin. Neurosci. 33 (2021) 201-209. https://doi.org/10.1176/appi.neuropsych.20100268.

[10] N.S. Narayanan, R.L. Rodnitzky, E.Y. Uc, Prefrontal dopamine signaling and cognitive symptoms of Parkinson's disease, Rev. Neurosci. 24 (2013) 267-278. https://doi.org/10.1515/revneuro-20130004.

[11] S. Ghosal, B.D. Hare, R.S. Duman, Prefrontal cortex GABAergic deficits and circuit dysfunction in the pathophysiology and treatment of chronic stress and depression, Curr. Opin. Behav. Sci. 14 (2017) 1-8. https://doi.org/10.1016/j.cobeha.2016.09.012.

[12] Y.-C. Kim, N.S. Narayanan, Prefrontal D1 Dopamine-Receptor Neurons and Delta Resonance in Interval Timing., Cereb. Cortex N. Y. N 1991. (2018). https://doi.org/10.1093/cercor/bhy083.

[13] A.Y. Deutch, Prefrontal cortical dopamine systems and the elaboration of functional corticostriatal circuits: implications for schizophrenia and Parkinson's disease, J. Neural Transm. Gen. Sect. 91 (1993) 197-221.

[14] M.S. George, T.A. Ketter, R.M. Post, Prefrontal cortex dysfunction in clinical depression, Depression. 2 (1994) 59-72. https://doi.org/10.1002/depr.3050020202.

[15] A. Primavera, P. Novello, Quantitative electroencephalography in Parkinson's disease, dementia, depression and normal aging, Neuropsychobiology. 25 (1992) 102-105. https://doi.org/10.1159/000118817.

[16] M.S. George, Z. Nahas, M. Molloy, A.M. Speer, N.C. Oliver, X.-B. Li, G.W. Arana, S.C. Risch, J.C. Ballenger, A controlled trial of daily left prefrontal cortex TMS for treating depression, Biol. Psychiatry. 48 (2000) 962-970. https://doi.org/10.1016/S0006-3223(00)01048-9.

[17] M.F. Anjum, S. Dasgupta, R. Mudumbai, A. Singh, J.F. Cavanagh, N.S. Narayanan, Linear predictive coding distinguishes spectral EEG features of Parkinson's disease, Parkinsonism Relat. Disord. 79 (2020) 79-85. https://doi.org/10.1016/j.parkreldis.2020.08.001. 
[18] A. Singh, R.C. Cole, A.I. Espinoza, A. Evans, S. Cao, J.F. Cavanagh, N.S. Narayanan, Timing variability and midfrontal $\sim 4 \square \mathrm{Hz}$ rhythms correlate with cognition in Parkinson's disease, NPJ Park. Dis. 7 (2021) 14. https://doi.org/10.1038/s41531-021-00158-x.

[19] A. Singh, R.C. Cole, A.I. Espinoza, D. Brown, J.F. Cavanagh, N.S. Narayanan, Frontal theta and beta oscillations during lower-limb movement in Parkinson's disease, Clin. Neurophysiol. Off. J. Int. Fed. Clin. Neurophysiol. 131 (2020) 694-702. https://doi.org/10.1016/j.clinph.2019.12.399.

[20] M.F. Anjum, J. Haug, S.L. Alberico, S. Dasgupta, R. Mudumbai, M.A. Kennedy, N.S. Narayanan, Linear Predictive Approaches Separate Field Potentials in Animal Model of Parkinson's Disease, Front. Neurosci. 14 (2020) 394. https://doi.org/10.3389/fnins.2020.00394.

[21] B.S. Atal, The history of linear prediction, IEEE Signal Process. Mag. 23 (2006) 154-161. https://doi.org/10.1109/MSP.2006.1598091.

[22] M. aan het Rot, S.J. Mathew, D.S. Charney, Neurobiological mechanisms in major depressive disorder, CMAJ Can. Med. Assoc. J. 180 (2009) 305-313. https://doi.org/10.1503/cmaj.080697.

[23] S. Zhao, J. Kong, S. Li, Z. Tong, C. Yang, H. Zhong, Randomized controlled trial of four protocols of repetitive transcranial magnetic stimulation for treating the negative symptoms of schizophrenia, Shanghai Arch. Psychiatry. 26 (2014) 15-21. https://doi.org/10.3969/j.issn.1002-0829.2014.01.003.

[24] I.H. Gotlib, EEG Alpha Asymmetry, Depression, and Cognitive Functioning, Cogn. Emot. 12 (1998) 449-478. https://doi.org/10.1080/026999398379673.

[25] R. Thibodeau, R.S. Jorgensen, S. Kim, Depression, anxiety, and resting frontal EEG asymmetry: A meta-analytic review, J. Abnorm. Psychol. 115 (2006) 715-729. https://doi.org/10.1037/0021843X.115.4.715.

[26] N. Jenkinson, P. Brown, New insights into the relationship between dopamine, beta oscillations and motor function, Trends Neurosci. 34 (2011) 611-618. https://doi.org/10.1016/j.tins.2011.09.003.

[27] J.L. Stewart, D.N. Towers, J.A. Coan, J.J.B. Allen, The oft-neglected role of parietal EEG asymmetry and risk for major depressive disorder, Psychophysiology. 48 (2011) 82-95. https://doi.org/10.1111/j.1469-8986.2010.01035.x.

[28] K. Liu, Q. Ma, M. Wang, Comparison of Quantitative Electroencephalogram During Sleep in Depressed and Non-Depressed Patients with Parkinson's Disease, Med. Sci. Monit. Int. Med. J. Exp. Clin. Res. 25 (2019) 1046-1052. https://doi.org/10.12659/MSM.913931.

[29] N.N.W. Dissanayaka, T.R. Au, A.J. Angwin, K.K. Iyer, J.D. O’Sullivan, G.J. Byrne, P.A. Silburn, R. Marsh, G.D. Mellick, D.A. Copland, Depression symptomatology correlates with event-related potentials in Parkinson's disease: An affective priming study, J. Affect. Disord. 245 (2019) 897904. https://doi.org/10.1016/j.jad.2018.11.094.

[30] R. Aiyer, V. Novakovic, R.L. Barkin, A systematic review on the impact of psychotropic drugs on electroencephalogram waveforms in psychiatry, Postgrad. Med. 128 (2016) 656-664. https://doi.org/10.1080/00325481.2016.1218261. 
medRxiv preprint doi: https://doi.org/10.1101/2022.02.16.22271060; this version posted February 19, 2022. The copyright holder for this preprint (which was not certified by peer review) is the author/funder, who has granted medRxiv a license to display the preprint in perpetuity.

It is made available under a CC-BY-NC-ND 4.0 International license.

Table S1: Demographic, disease, non-motor, motor, and cognitive characteristics

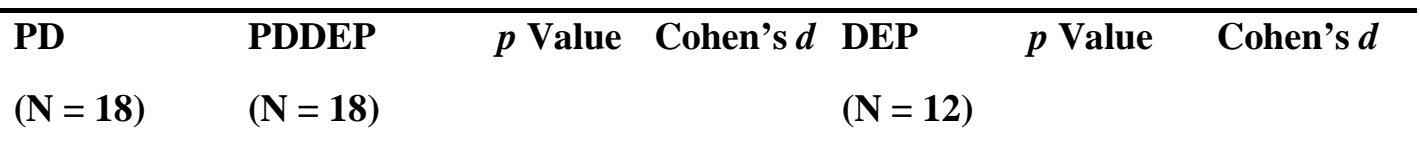

\section{Demographics and Disease}

Gender, $\mathrm{M} / \mathrm{F}$

$11 / 7$

$14 / 4$

$68.3(2.0)$

$65.8(1.7)$

${ }^{\mathrm{a}} 0.23$

${ }^{\mathrm{a}} 0.32$

$62.1(1.8) \quad{ }^{\mathrm{b}} 0.17$

${ }^{\mathrm{b}} 0.54$

Disease duration, years

$4.4(0.5)$

$6.7(0.9)$

${ }^{\mathrm{a}} 0.12$

${ }^{\mathrm{a}} 0.70$

$23.7(4.6) \quad{ }^{b}<0.01$

${ }^{\mathrm{b}} 1.64$

LEDD, mg/day

$838.6(98.1)$

$983.8(135.5)$

${ }^{\mathrm{a}} 0.60$

${ }^{\mathrm{a}} 0.29$

\section{Cognition Characteristics}

MOCA (0-30)

$23.6(1.0)$

$23.6(0.9)$

${ }^{\mathrm{a}} 0.94 \quad{ }^{\mathrm{a}} 0.01$

$26.8(0.6) \quad{ }^{b} 0.03$

${ }^{\mathrm{b}} 0.97$

\section{Non-Motor Characteristics}

GDS (0-15)

PHQ-9 (0-27)

\section{Motor Characteristics}

UPDRS III (0-56)
$2.2(0.3)$

$8.4(0.7)$

${ }^{\mathrm{a}}<0.01$

a 2.91
$15.9(1.6)$ 
391 aNon-parametric Wilcoxon test was used for comparison between PD vs PDDEP subjects. ${ }^{\text {b Non- }}$ 392 parametric Wilcoxon test was used for comparison between PDDEP vs DEP subjects. 393 Abbreviations: Male, M; Female, F; Montreal Cognitive Assessment, MOCA; Geriatric Depression 394 Scale, GDS; Patient Health Questionnaire-9, PHQ-9; motor Unified Parkinson's Disease Rating Scale, $395 \quad$ UPDRS III. 
medRxiv preprint doi: https://doi.org/10.1101/2022.02.16.22271060; this version posted February 19, 2022. The copyright holder for this preprint (which was not certified by peer review) is the author/funder, who has granted medRxiv a license to display the preprint in perpetuity.

It is made available under a CC-BY-NC-ND 4.0 International license.

397 Table S2: Truncation analysis accuracy across datasets

398

\begin{tabular}{|l|l|l|l|l|l|l|}
\hline Dataset & \multicolumn{3}{|c|}{ DEP vs PDDEP } & \multicolumn{3}{c|}{ PD vs PDDEP } \\
\hline TF Channel & CPz & CP4 & CPz + CP4 & CP3 & TP8 & CP3 + TP8 \\
\hline 0.05 & $75 \%$ & $58.3 \%$ & $66.7 \%$ & $52.78 \%$ & $55.6 \%$ & $61.1 \%$ \\
\hline 0.33 & $79.2 \%$ & $75 \% \%$ & $83.3 \%$ & $61.1 \%$ & $61.1 \%$ & $66.7 \%$ \\
\hline 0.66 & $91.7 \%$ & $95.8 \%$ & $95.8 \%$ & $72.2 \%$ & $61.1 \%$ & $75 \%$ \\
\hline 1 & $95.8 \%$ & $91.7 \%$ & $100 \%$ & $86.1 \%$ & $86.1 \%$ & $97.2 \%$ \\
\hline
\end{tabular}

399

400 
medRxiv preprint doi: https://doi.org/10.1101/2022.02.16.22271060; this version posted February 19, 2022. The copyright holder for this preprint (which was not certified by peer review) is the author/funder, who has granted medRxiv a license to display the preprint in perpetuity.

\section{It is made available under a CC-BY-NC-ND 4.0 International license .}

401 
A Detal(1-1-4Hz)
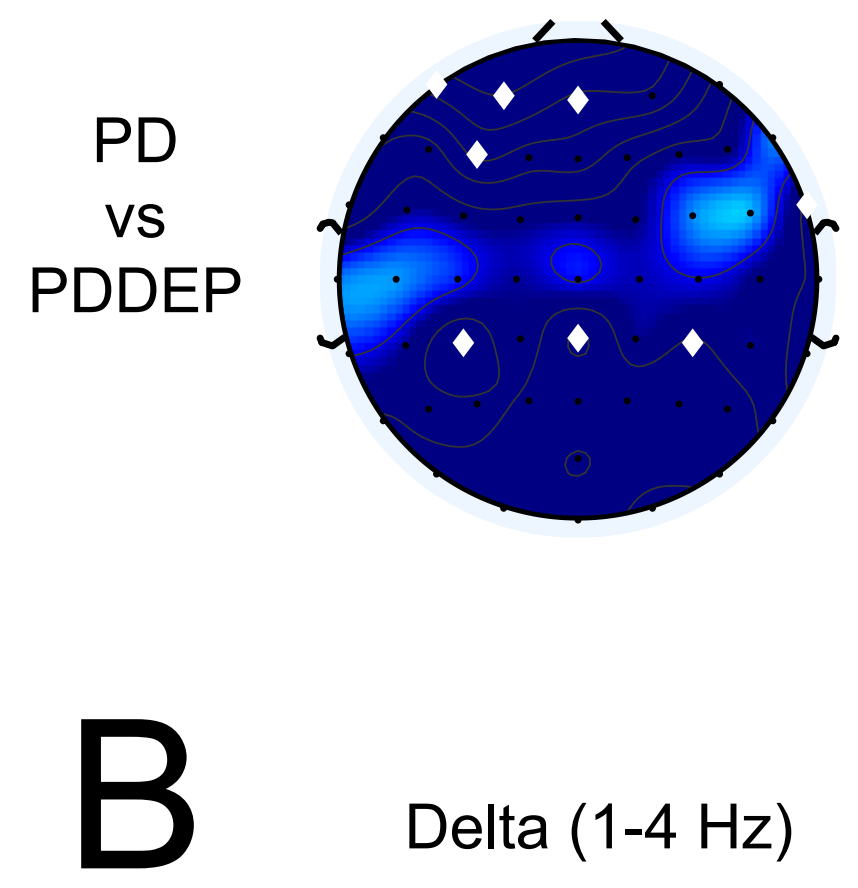

Delta (1-4 Hz)

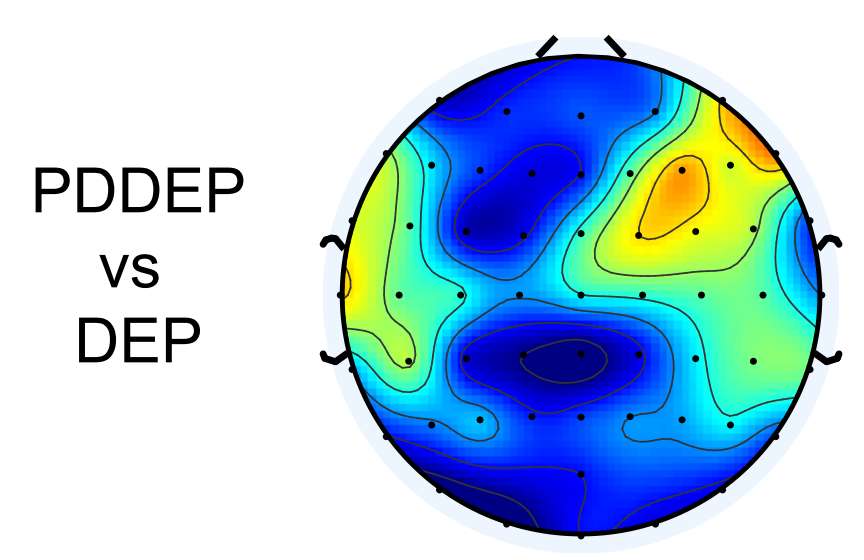

Theta $(4-8 \mathrm{~Hz})$

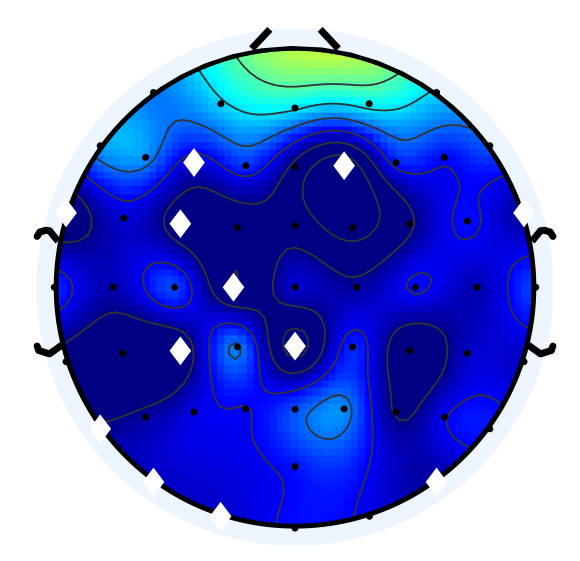

Alpha (8-13 Hz)
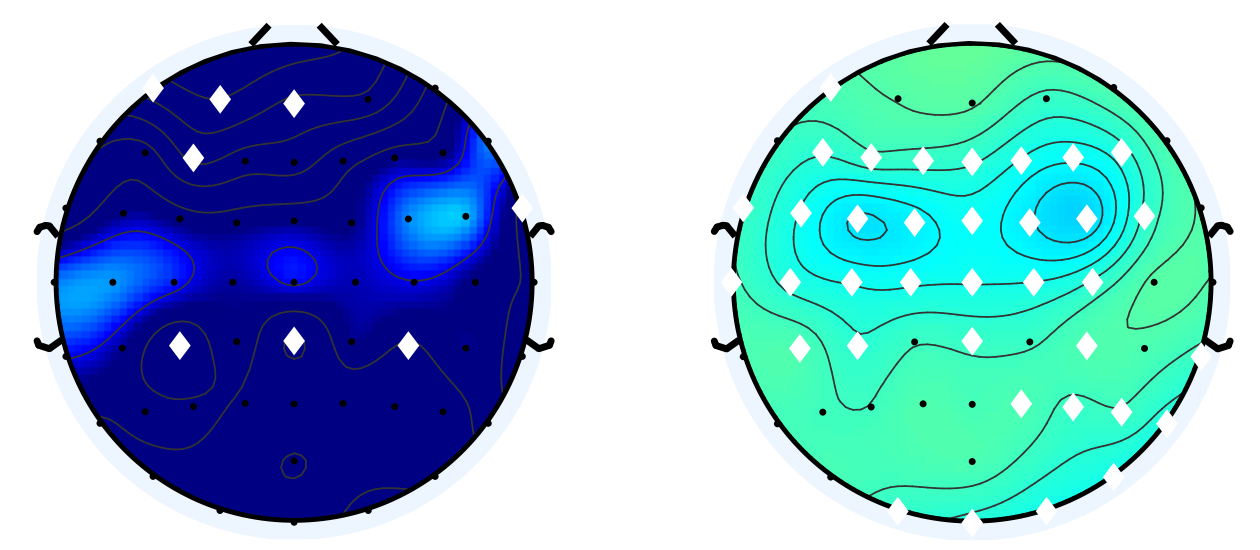

Alpha $(8-13 \mathrm{~Hz})$
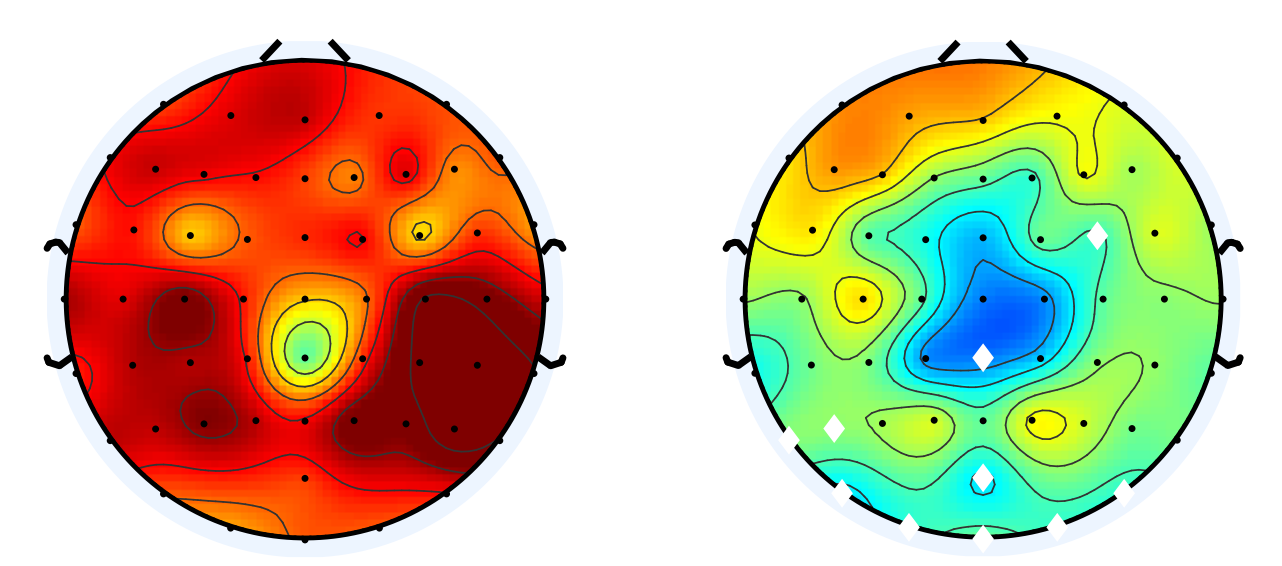

Beta $(13-30 \mathrm{~Hz})$

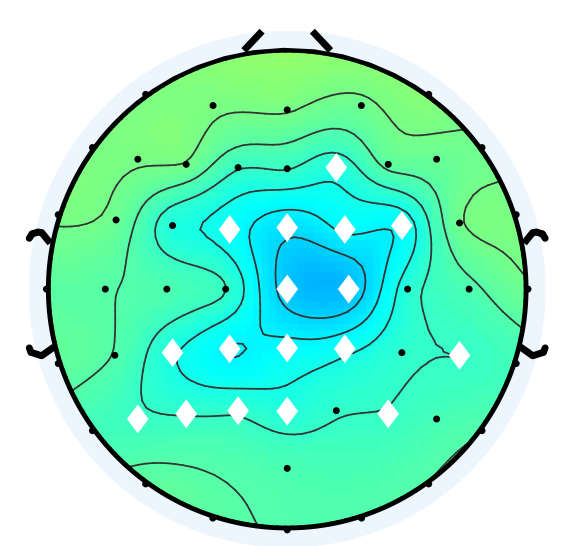

Gamma $(30-80 \mathrm{~Hz})$
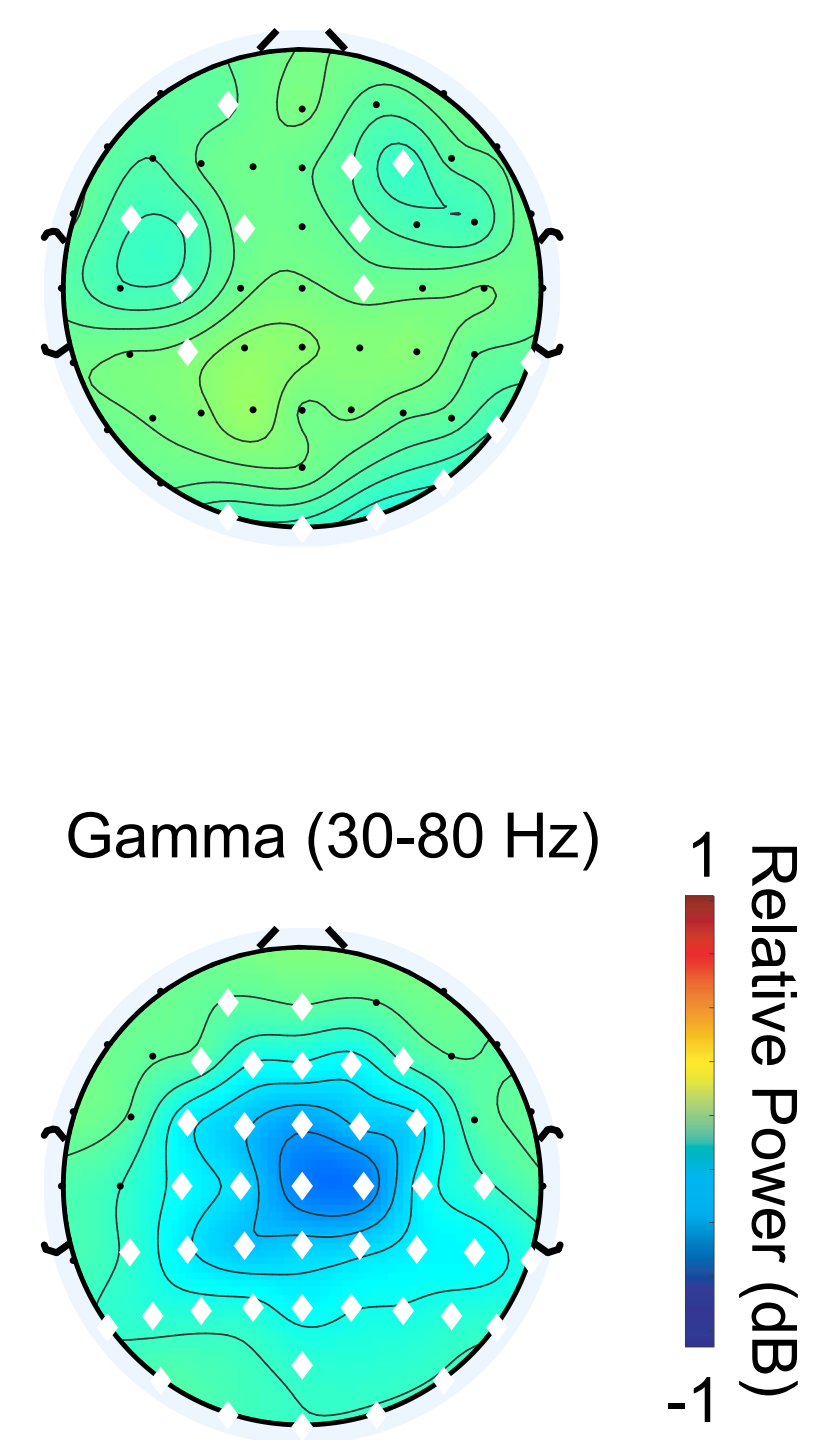


\section{Raw Data \\ EEG Signal}

$\downarrow$

Normalize Energy

$\downarrow$

Bandpass Filter

$\downarrow$

Feature Extraction using LPC

\section{Classification}

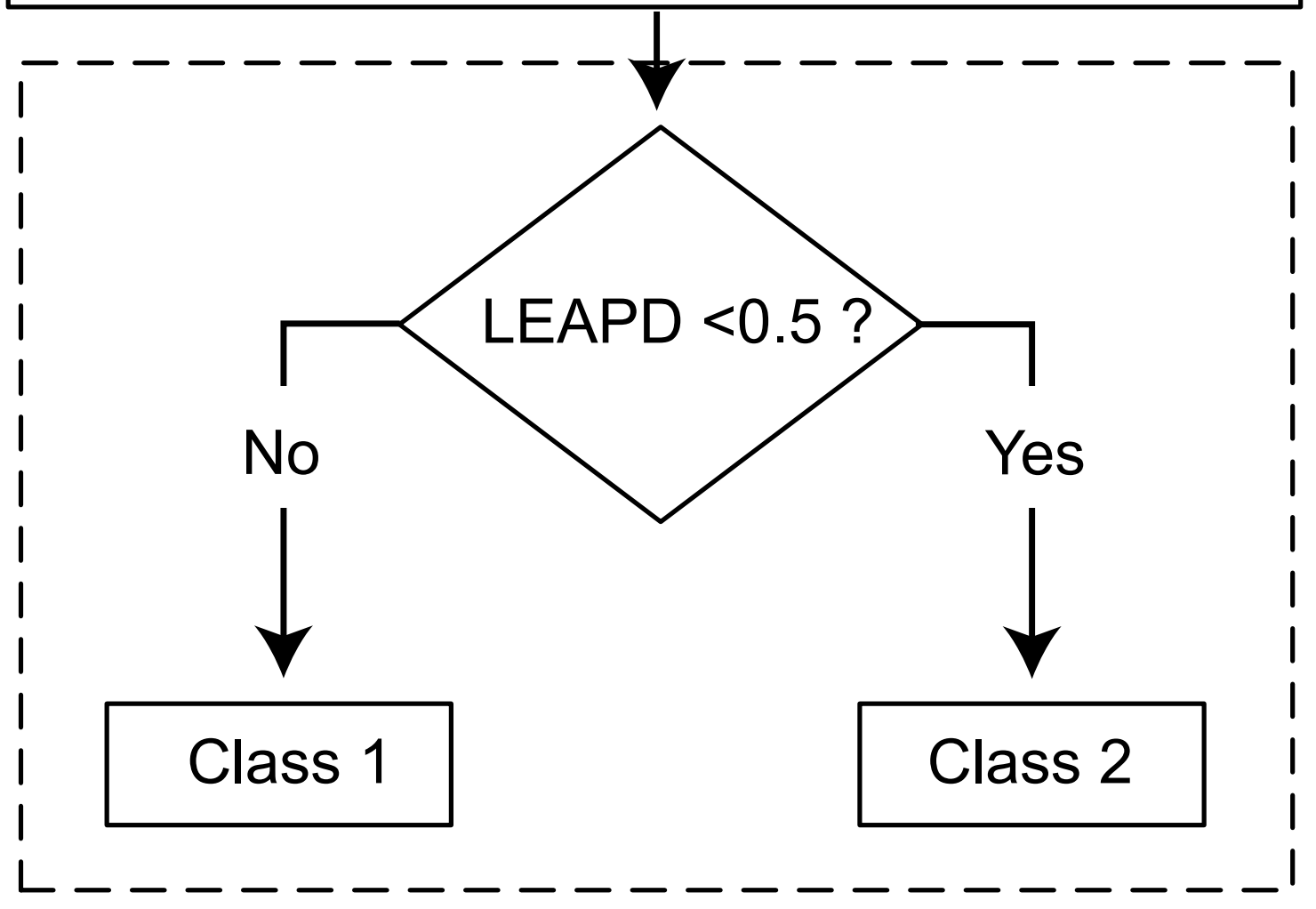

Binary Classification 
A PD vs. PDDEP $\quad B \quad C$
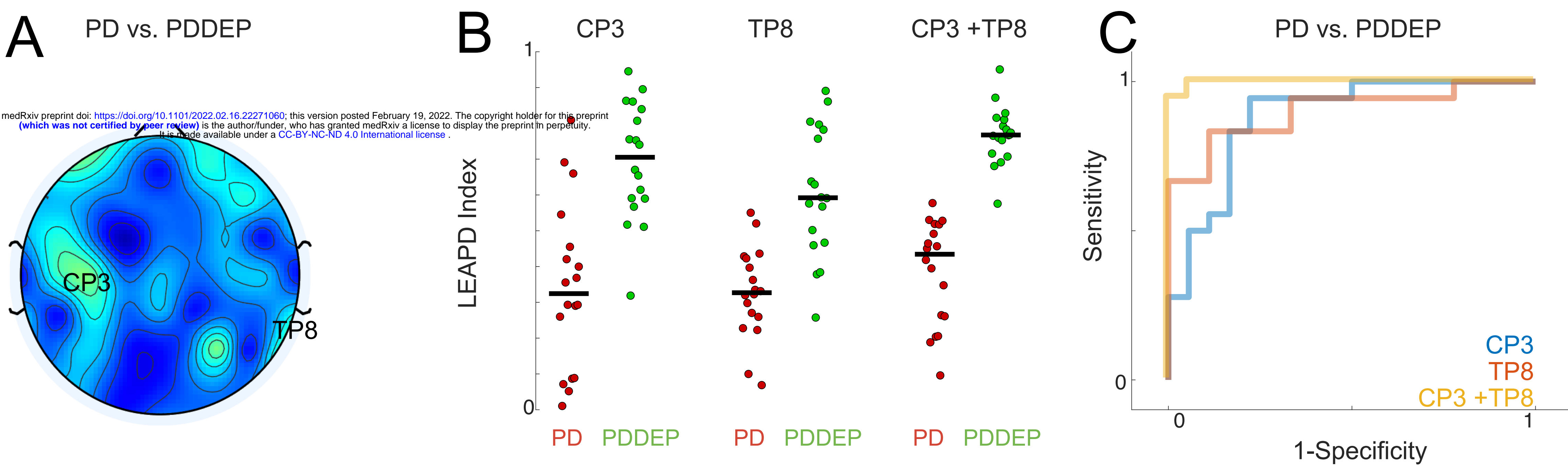

D PDDEP vs DEP
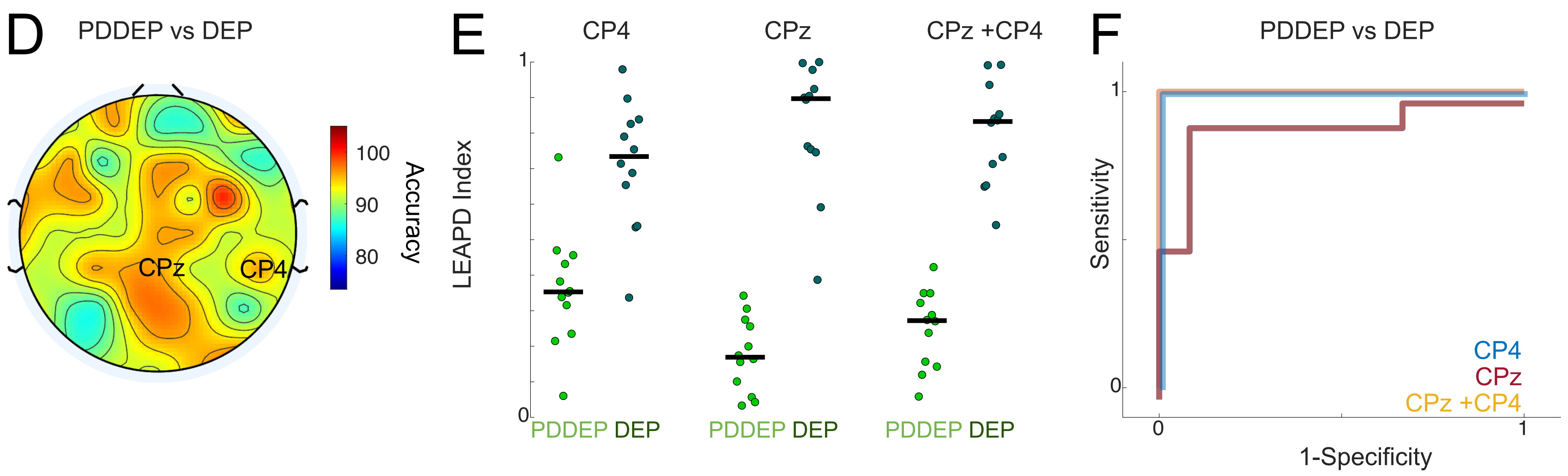
$A$

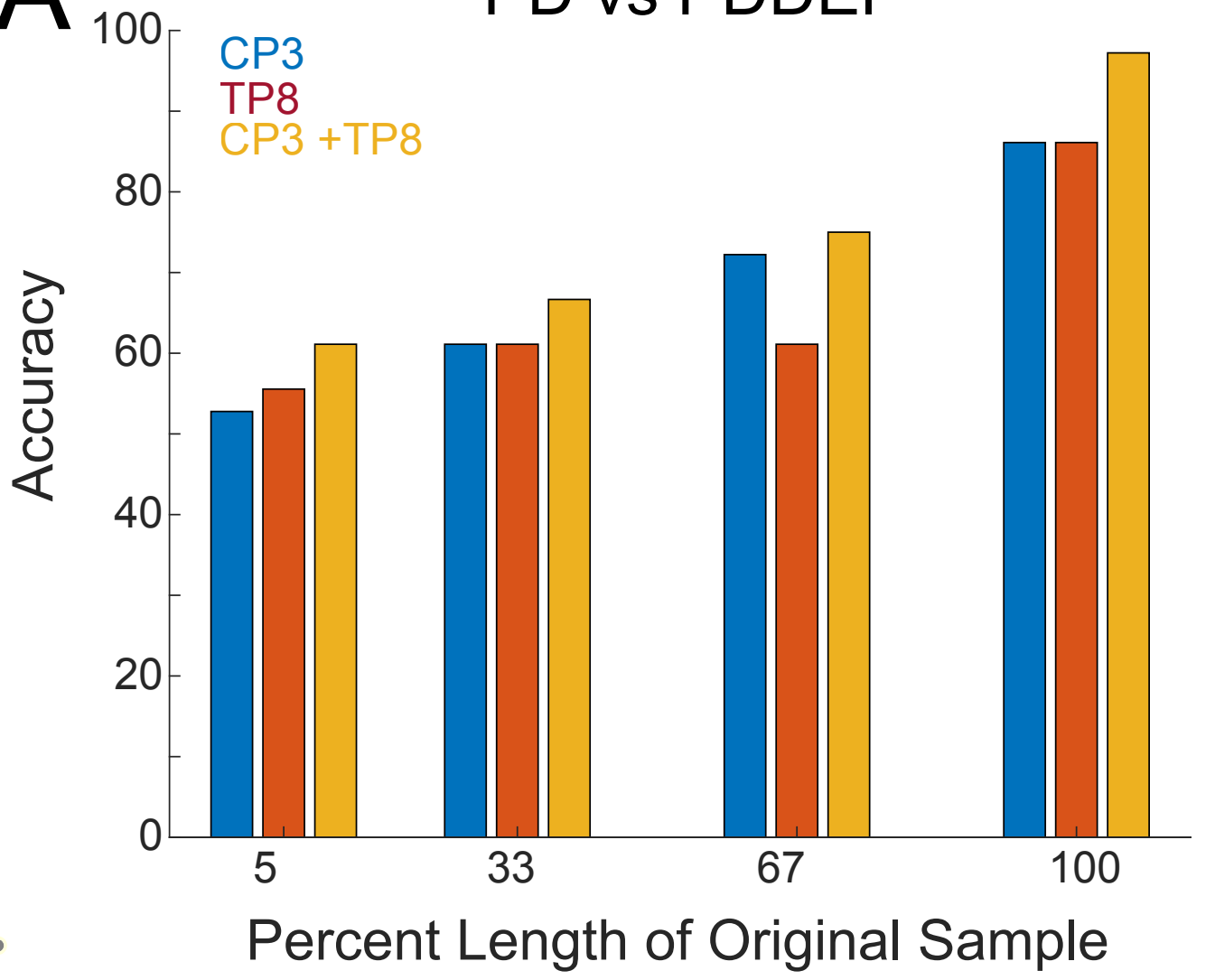

$B_{100} \quad$ DEP vs PDDEP

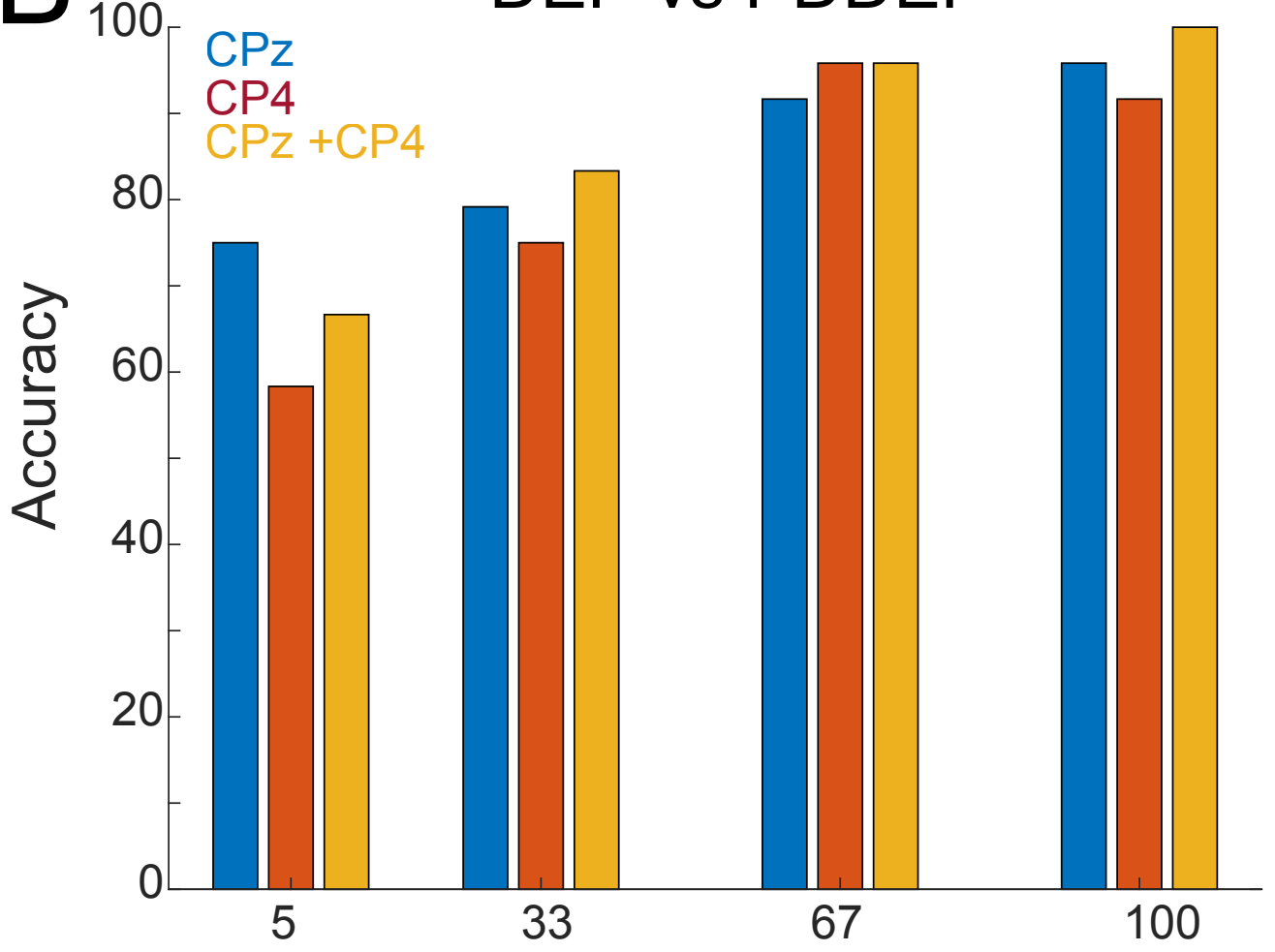

Percent Length of Original Sample 